\title{
The peripartum management of a 32-year-old patient presenting at 34 weeks' gestation with unrepaired cyanotic heart disease
}

\author{
J N Rossouw, ${ }^{1} \mathrm{MB}$ ChB, FCOG (SA); M Bryan, ${ }^{1} \mathrm{MB}$ ChB, FCOG (SA); E Langenegger, ${ }^{1} \mathrm{MB}$ ChB, FCOG (SA), PhD; \\ J Burke, ${ }^{1} \mathrm{MB}$ ChB, FCA (SA); A van Rensburg, ${ }^{2} \mathrm{MB}$ ChB, FCP (SA), MMed (Internal Med), Cert Cardiology (SA); \\ A Pecoraro, ${ }^{2} \mathrm{MB}$ ChB, MMed (Internal Med), FCP (SA), Cert Cardiology (SA)
}

${ }^{1}$ Department of Obstetrics and Gynaecology, Tygerberg Hospital and Stellenbosch University, Cape Town, South Africa

${ }^{2}$ Department of Cardiology, Tygerberg Hospital and Stellenbosch University, Cape Town, South Africa

Corresponding author: J N Rossouw (jnrossouw@yahoo.com)

\begin{abstract}
Unrepaired cyanotic heart disease is considered a high-risk lesion owing to the consequent increase in maternal and fetal complications. In the presence of pulmonary hypertension, maternal mortality approaching $50 \%$ has been reported, and pregnancy is therefore considered contraindicated. We present a case of a 32-year-old woman presenting at 34 weeks' gestation in heart failure due to newly diagnosed cyanotic complex cardiac disease. The diagnosis of left atrial isomerism with a common atrium, single atrioventricular valve, and a restrictive ventricular septum defect was made. Cyanosis was due to mixing at atrial level, without features of Eisenmenger's syndrome. Her intrapartum multidisciplinary management is described in detail. The patient was discharged home in a condition similar to her baseline, together with her healthy neonate.
\end{abstract}

S Afr J Obstet Gynaecol 2018;24(2):36-39. DOI:10.7196/SAJOG.2018.v24i2.1265

Unrepaired cyanotic cardiac lesions are considered a high-risk (World Health Organization class 3) maternal condition, but pulmonary hypertension, irrespective of the cause, is a class 4 disease, and pregnancy is considered contraindicated. The presence of pulmonary hypertension in pregnancy is associated with adverse outcomes for both the mother and the fetus, with a maternal mortality risk historically ranging between 30 and $50 \%$. Even with modern treatment, mortality is still very high, and ranges between 17 and $33 \%{ }^{[1]}$ We report on the successful outcome of a pregnancy in a 32-year-old woman with newly diagnosed complex cyanotic heart disease, presenting with progressive shortness of breath at 34 weeks' gestation.

\section{Case presentation}

A 32-year-old pregnant woman was admitted to hospital because of severe shortness of breath, at 34 weeks' gestation. She was referred to our unit from her local midwife obstetric unit after she presented with a 1-week history of a dry cough, swelling of the lower limbs and progressive shortness of breath associated with all activities (including lying down). The initial observations and blood gas are recorded in Tables 1 and 2. There was no history of fever. She had no previous medical diseases, and tested negative for HIV and syphilis. There was no surgical history of note. She reported normal effort tolerance (New York Heart Association Grade I) prior to her presentation. She was married, and had a healthy 8-year-old child. Remarkably, this son was born in 2008 at term, with what was described as an uncomplicated antenatal period and a normal vaginal delivery. Her further obstetric history included four firsttrimester losses without an identifiable cause. She booked early for antenatal care in the index pregnancy at her local clinic.

On examination, she was cyanotic with an oxygen saturation of $85 \%$, with no improvement with use of a $40 \%$ fixed performance
Table 1. Maternal vital signs

\begin{tabular}{ll}
\hline Observations & \\
\hline Blood pressure & $131 / 66 \mathrm{mmHg}$ \\
Respiratory rate & 28 breaths/minute \\
Pulse rate & $92 \mathrm{bpm}$ \\
Temperature & $36.7^{\circ} \mathrm{C}$ \\
Oxygen saturation & $85 \%$ (on $40 \%$ facemask)
\end{tabular}

Table 2. Initial blood gas

\begin{tabular}{ll}
\hline Blood gas (arterial) & \\
\hline $\mathrm{pH}$ & 7.42 \\
$\mathrm{paCO}_{2}$ & $4.5 \mathrm{kPa}$ \\
$\mathrm{paO}_{2}$ & $6.4 \mathrm{kPa}$ \\
$\mathrm{Lactate}$ & $1.1 \mathrm{mmol} / \mathrm{L}$ \\
Base excess & $-1.7 \mathrm{mmol} / \mathrm{L}$ \\
Bicarbonate & $23.2 \mathrm{mmol} / \mathrm{L}$
\end{tabular}

device oxygen mask. She had prominent clubbing in both her upper and lower extremities. Her jugular venous pressure waveform was raised, and marked peripheral oedema was present. She had prominent features of pulmonary hypertension, including a parasternal heave and a loud second heart sound (P2). Her apex beat was displaced laterally, and a 3/6 pansystolic murmur was audible over the left sternal border. Her abdominal examination confirmed a 34-week pregnancy of a well-grown baby, and she showed no signs of preterm labour.

Her electrocardiogram revealed a sinus rhythm with an abnormal P-wave axis $\left(-30^{\circ}\right)$, dilated left atrium with a superior QRS axis and features of right ventricular hypertrophy (dominant R wave V1, RV strain pattern) (Fig. 1). An echocardiogram was performed, 
and revealed the presence of left atrial isomerism (common atrium, interrupted inferior vena cava and bilateral left atrial appendages). In our patient, left isomerism resulted in the presence of two left symmetrical bilobed lungs, polysplenia, a transverse liver (centrally positioned) and a left-sided stomach bubble (Figs 2 - 4). Two morphological left atria with complete absence of the interatrial septum were visualised. Additional findings were that of a single atrioventricular (AV) valve with a restrictive ventricular septal defect (VSD) (Fig. 2). Both the right and left side of the AV were functioning well, and she had normal systolic function of both ventricles. There was echocardiographic evidence of severe pulmonary hypertension, with an estimated peak pulmonary pressure (based on mild right $\mathrm{AV}$ valve incompetence jet) of $55 \mathrm{mmHg}$ plus atrial pressure. The left $\mathrm{AV}$ valve was competent, and there was normal ventriculoarterial concordance, with no abnormality of the semilunar valves or great arteries. We concluded that the cyanosis was caused by mixing of blood in the common atrium. Unfortunately, she declined

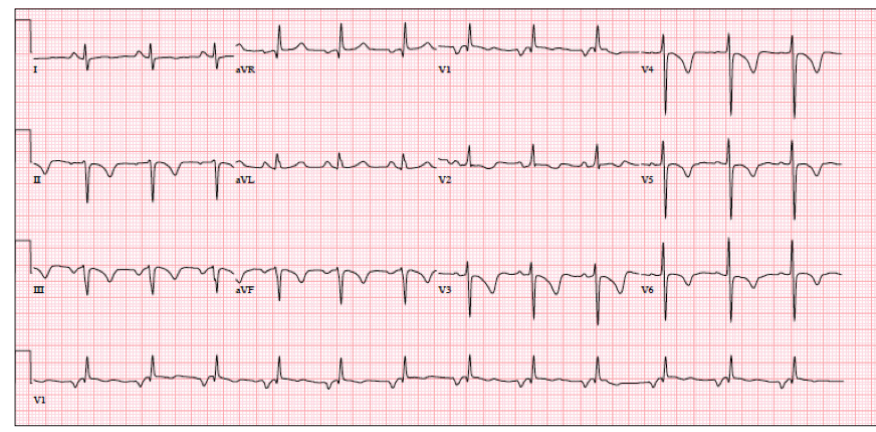

Fig. 1. The ECG demonstrates sinus rhythm (although P-wave axis abnormal at $-30^{\circ}$ ), dilated LA, superior $Q R S$ axis with features of right ventricular hypertrophy (dominant $R$ wave V1). (ECG = electrocardiogram; $L A=$ left atrium.)

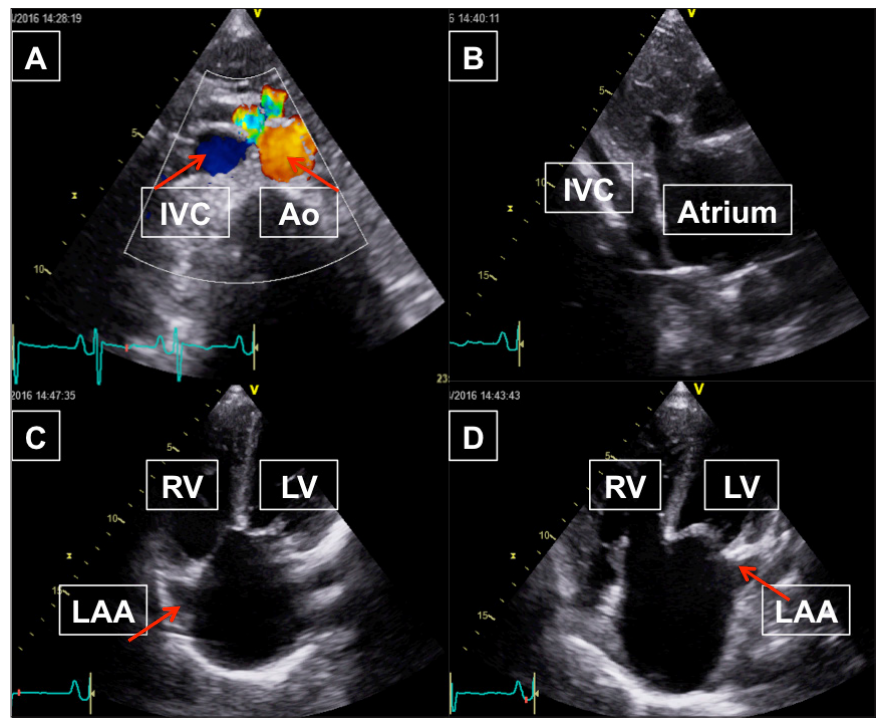

Fig. 2. Echocardiogram (maternal). A: Subcostal short axis view (situs view) suggesting situs solitus, with the aorta (Ao, arrow) to the left of the vertebral column. B: Subcostal view with the inferior vena cava (arrow, IVC) not connecting to an atrium, taking a course posterior to the atria to connect to the azygos system. $C$ and D: An apical fourchamber view demonstrates a common atrium, two morphologically left atrial appendages (arrows, LAA) and single AV valve. (Images courtesy of the Department of Cardiology, University of Stellenbosch and Tygerberg Hospital, Cape Town, South Africa.) postdelivery imaging and invasive haemodynamic assessment, and the presence of right-to-left shunts at the arterial level (patent ductus arteriosus) is still a possibility.

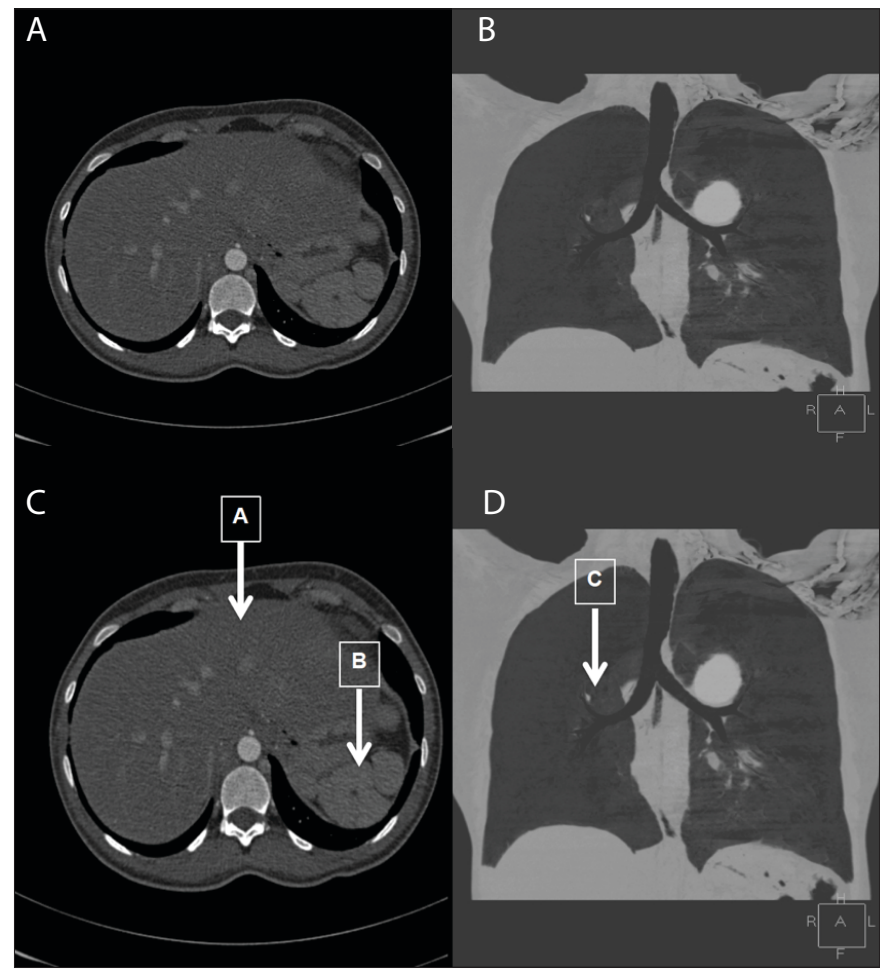

Fig. 3. Computed tomography (chest) A: Centrally positioned (transverse) liver. B: Polysplenia is apparent. C: The right main bronchus divides into two lobar bronchi instead of three as seen in normal bronchial development. (Images courtesy of the Department of Cardiology, University of Stellenbosch and Tygerberg Hospital, Cape Town, South Africa.)

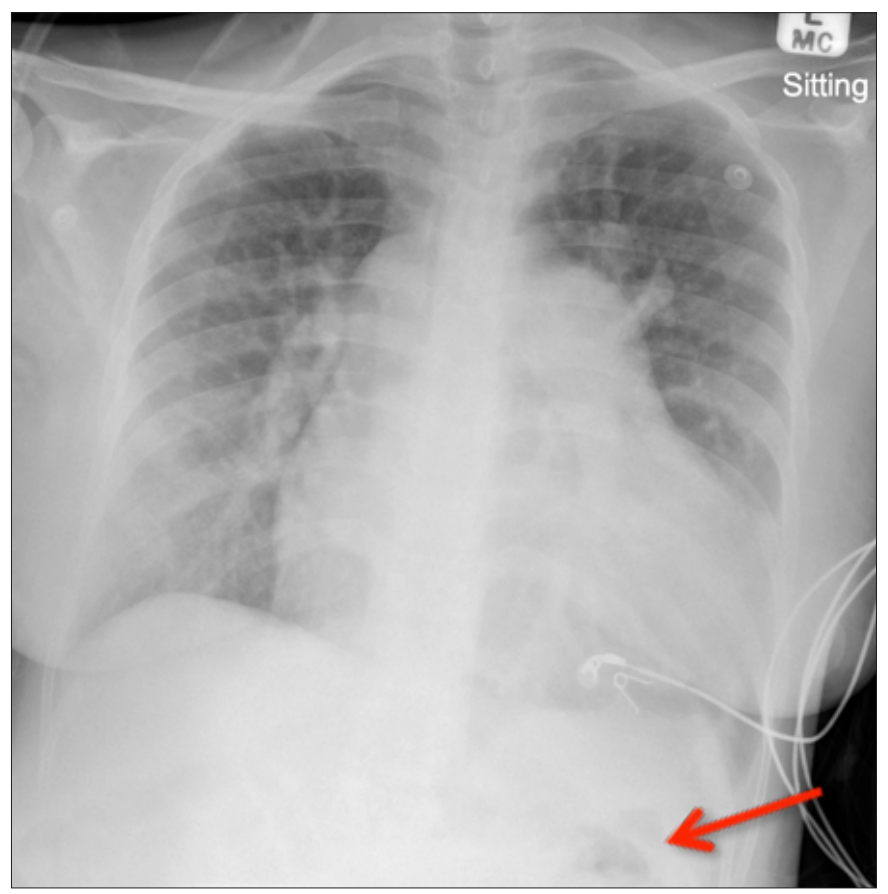

Fig. 4. X-ray (chest) A: The stomach bubble is visible under the left hemi-diaphragm (arrow). (Images courtesy of the Department of Cardiology, University of Stellenbosch and Tygerberg Hospital, Cape Town, South Africa.) 
The patient was admitted to the obstetric critical care unit (OCCU). Diuretics (furosemide) were administered, as well as non-invasive ventilation with continuous positive end expiratory pressure on inspiratory oxygen concentrations of $80-95 \%\left(\mathrm{FiO}_{2}\right)$. A multidisciplinary team managed the patient and planned the delivery. Once the patient was stabilised, a fetal cardiotocograph was performed, and was normal. The decision was taken to deliver by caesarean section. Comorbidities were excluded.

\section{Perioperative management}

The patient received premedication including: $30 \mathrm{~mL}$ sodium citrate per mouth, $10 \mathrm{mg}$ metochlopramide and $1.2 \mathrm{~g}$ of amoxicillinclavulanic acid intravenously. A central venous line was inserted through the internal jugular vein, and an arterial line was placed, under local anaesthesia. A dobutamine infusion was commenced at $5 \mu \mathrm{g} / \mathrm{kg} / \mathrm{min}$. An infusion of Ringer's lactate at $50 \mathrm{~mL} / \mathrm{h}$ was commenced before the lumbar (L2-3) epidural was loaded over 30 minutes, with $15 \mathrm{~mL} 2 \%$ lignocaine in $5 \mathrm{~mL}$ incremental boluses. The patient was positioned supine, wedged $30^{\circ}$ left lateral and received oxygen via a $40 \%$ facemask. An adequate T4 sensory block was obtained.

Systemic arterial blood pressures were maintained around 120/60 mmHg, pulse rate 80 - $100 \mathrm{bpm}$, while central venous pressure readings ranged from $10-17 \mathrm{cmH}_{2} \mathrm{O}$. Phenylephrine was given in $50 \mu \mathrm{g}$ boluses targeting the baseline blood pressure (total $300 \mu \mathrm{g}$ ).

The caesarean section proceeded without event. Once the umbilical cord was clamped, an oxytocin infusion at a rate of $10 \mathrm{IU} / \mathrm{h}$ resulted in good contraction of the uterus, and was continued in the early postpartum period.

At the uncomplicated caesarean section, a $2040 \mathrm{~g}$ male baby was delivered, with Apgars of 9/10/10 (1 min, $5 \mathrm{~min}, 10 \mathrm{~min}$ ). A sterilisation procedure was performed at the time of surgery.

\section{Postpartum}

The patient was admitted to the OCCU for postoperative monitoring and supportive care. Further management included epidural regional pain relief with an infusion of bupivacaine $0.1 \%$, and fentanyl $2 \mu \mathrm{g} / \mathrm{mL}$ at a rate of $10 \mathrm{~mL} / \mathrm{h}$. Phenylephrine infusion maintained normotension and a mean arterial pressure above $90 \mathrm{mmHg}$. Intravenous trinitroglicerine $(1-3 \mu \mathrm{g} / \mathrm{min})$ and oral sildenafil (10 mg 8-hourly per os) were administered to reduce pulmonary vascular resistance. The patient remained in OCCU for 7 days for observation. The patient recovered well, and was able to take care of her baby and breastfeed. She was fit for discharge from the hospital 15 days after delivery, in a stable condition with a baseline oxygen saturation on room air of $86 \%$.

Her follow-up at 6 weeks was unremarkable, and both mother and baby were well. Future imaging with left and right heart studies were planned. The patient, however, declined further investigation or intervention.

\section{Discussion}

South African maternal mortality due to cardiac conditions comprises $34.5 \%$ of all medical and surgical causes of maternal deaths. Medical and surgical causes together make up the 4th most common cause of such mortality, and are also responsible for $11.3 \%$ of total maternal deaths. In developing countries, complex cardiac abnormalities may present with delayed diagnosis. ${ }^{[2]}$ On presentation, prompt critical care monitoring, multidisciplinary management and planned delivery may increase the likelihood of a good outcome in a patient with an expected high risk of mortality.

Heterotaxy (hetero 'different' and taxy 'arrangement') refers to the abnormal assembly of the thoracic and abdominal organs with regards to the left-right axis of the body. In these patients, the normal asymmetry of the thoracic and abdominal organs is lost, resulting in an unusual degree of symmetry of organs and veins. This complex syndrome presents with complex cardiovascular anomalies, and describing the specific variation in the specific patient is important, including the morphology of the spleen and intra-abdominal organs. The spleen should, however, not be used to assign sidedness of the heterotaxy, as it is not as accurate as the atrial appendages or bronchial tree morphology in predicting left- or right-sidedness correctly. It is important to assign situs being solitus (normal), inversus (mirror-image) or ambiguous. ${ }^{[3]}$

Right atrial isomerism (iso 'equal' and meros 'part') is diagnosed when two morphologically right atria are associated with their rightsided atrial appendages. There is absence of a morphologically left atrium and coronary sinus. Other cardiac abnormalities include anomalous pulmonary venous drainage and variable degrees of pulmonary outflow obstruction, and the heart usually functions as a single ventricle. ${ }^{[4,5]}$ In left atrial isomerism, both atria are morphologically left atria, and are accompanied by left atrial appendages, an interrupted inferior vena cava, two bilobed lungs, enlarged azygos vein and variable cardiac abnormalities. ${ }^{[4-6]}$ More than half of all patients with either right or left isomerism have a single AV valve. ${ }^{[7]}$ Our patient demonstrated the most common abnormalities encountered in left atrial isomerism, namely a single $\mathrm{AV}$ valve, interrupted inferior vena cava and a ventricular septal defect. $^{[8]}$

Atrial isomerism is rare, and occurs in approximately 1.1/1 000 live births. ${ }^{[9]}$ Of all congenital heart defects, heterotaxy has the highest risk of familial recurrence ${ }^{[10]}$ The exact molecular mechanism of heterotaxy/isomerism is still under investigation. ${ }^{[1]}$ Multiple gene mutations (transforming growth-factor beta family) have been identified as associated with this syndrome. ${ }^{[12]}$ Heterotaxy is also more common in offspring of women with maternal diabetes mellitus (pregestational). ${ }^{[13]}$

Only one case report of heterotaxy in pregnancy could be found in a literature search. The 26-year-old patient's specific anomalies included: a persistent left superior vena cava draining into the left coronary sinus, an interrupted inferior vena cava, absent azygos vein, bilateral bilobed lungs and polysplenia. This patient presented at 13 weeks' gestation with sudden collapse due to massive, bilateral pulmonary emboli. She survived, and at 20 weeks, evidence of fetal ischaemic injury (ventriculomegaly/hydranencephaly and hydrops) was noted. Her pregnancy was terminated at 25 weeks owing to hypertensive complications. ${ }^{[14]}$

Our patient had an uncomplicated antenatal history, and presented unwell for the first time at 34 weeks' gestation. Pregnancy is a cardiovascular challenge to all cardiac patients, in view of the haemodynamic changes $(50 \%$ increased plasma volume due to haemodilution) occurring from the first trimester, gradually increasing into the third trimester, and peaking in labour and immediately postpartum. These physiological changes led to our patient's presentation of shortness of breath.

Cyanotic congenital heart disease occurs in $9.5 \%$ of all congenital cardiac defects, and $62 \%$ of these patients are women. ${ }^{[15]}$ Women in their reproductive years face special risks, in view of the potential 
for pregnancy complications. The outcomes of pregnancies in patients with cyanotic lesions found fetal survival to be $92 \%$ if the maternal arterial oxygen saturation was $90 \%$ or more, but with saturation below $85 \%$, the fetal survival was only $12 \%$. Miscarriage, preterm birth and low birth weight are also more common in pregnancies complicated by cyanotic heart lesions. Thrombotic complications (pulmonary and cerebral) may ensue, but routine anticoagulation is not advisable, although in the single other case of heterotaxy in the literature thrombosis did occur, with an uncertain aetiology. ${ }^{[14,16]}$ Having a cyanotic cardiac lesion is considered an independent risk factor for poor maternal, neonatal and obstetric outcome $(p<0.0001)$. $^{[17]}$

Most cases of cyanotic congenital heart disease in the literature had concomitant Eisenmenger's syndrome (ES), which in itself increases the risks of the pregnancy. ES (right-to-left shunt across an interatrial/interventricular defect or aortic-pulmonary shunt) has a predicted risk of mortality in pregnancy from $16 \%$ (newer data) to $36 \%$ (older data). ${ }^{[18,19]}$ Our case did not have ES, and can therefore not be directly compared with these cases.

Long-term outcome and survival depend on the specific cardiac lesion. Left-sided heterotaxy generally has an increased survival rate compared with right-sided heterotaxy, as the cardiac lesions are frequently less severe ${ }^{[4]}$ which is illustrated by this patient surviving pregnancy with good maternal and neonatal outcomes.

\section{Conclusion}

Ideally, patients with complex cardiac defects should present before conception. This would allow the correct diagnosis to be made, and an understanding of the physiology and extent of the cardiac lesion prior to pregnancy. Meticulous planning of optimal medical and surgical management in a multidisciplinary team is imperative. It is, however, still important to discourage patients with severe cardiac anomalies from embarking on pregnancy.

Acknowledgments. We would like to thank the Departments of Cardiology and Radiology of Tygerberg Hospital and the University of Stellenbosch, for providing us with the images used in the case report.

Author contributions. JNR: First author, writing of article, collaboration between departments, treating obstetrician. MB: Treating obstetrician-in-training, note- keeping. EL: Overseeing consultant in OCCU. JB: Anaesthesiologist overseeing case, writing of article. AvR and AP: Treating cardiologists, writing of article.

Conflicts of interest. None.

Funding. None.

1. European Society of Gynecology (ESG), Association for European Paediatric Cardiology (AEPC), German Society for Gender Medicine (DGesGM), et al. ESC guidelines on the management of cardiovascular diseases during pregnancy: The Task Force on the Management of Cardiovascular Diseases during Pregnancy of the European Society of Cardiology (ESC). Eur Heart J 2011;32(34):3147-3197. https://doi.org/10.1093/eurheartj/ehr218

2. National Department of Health, South Africa. Saving Mothers 2011 - 2013: Sixth Report on the Confidential Enquiries into Maternal Deaths in South Africa. NDoH: Pretoria, 2015.

3. Jacobs JP, Anderson RH, Weinberg PM, et al. The nomenclature, definition and classification of cardiac structures in the setting of heterotaxy. Cardiol Young 2007;17(Suppl 2):S1-S28. https://doi org/10.1017/S1047951107001138

4. Sapire DW, Ho SY, Anderson RH, Rigby ML. Diagnosis and significance of atrial isomerism. Am J Cardiol 1986;58(3):342-346.

5. Stanger P, Rudolph AM, Edwards JE. Cardiac malpositions. An overview based on study of sixty-five necropsy specimens. Circulation 1977;56(2):159-172.

6. Van Praagh R, Van Praagh S. Atrial isomerism in the heterotaxy syndromes with asplenia, or polysplenia, or normally formed spleen: An erroneous concept. Am J Cardiol 1990;66(20):1504-1506.

7. Stamm C, Friehs I, Duebener LF, Zurakowski D, Mayer JE Jr, Jonas RA, del Nido PJ. Improving results of the modified Fontan operation in patients with heterotaxy syndrome. Ann Thorac Surg 2002;74(6):1967-1977.

8. Cohen MS, Schultz AH, Tian Z, et al. Heterotaxy syndrome with functional single ventricle: Does prenatal diagnosis improve survival? Ann Thorac Surg 2006;82:1629-1636. https://doi. org/10.1016/j.athoracsur.2006.05.039

9. Lin $\mathrm{AE}$, Krikov S, Riehle-Colarusso $\mathrm{T}$, et al. Laterality defects in the national birth defects prevention study (1998-2007): Birth prevalence and descriptive epidemiology. Am J Med Genet 2014;164A(10): 2581-2591. https://doi.org/10.1002/ajmg. a.36695.

10. Øyen N, Poulsen G, Wohlfahrt J, et al. Recurrence of discordant congenital heart defects in families. Circ Cardiovasc Genet 2010;3(2):122-128. https://doi.org/10.1161/CIRCGENETICS.109.890103.

11. Chen CM1, Norris D, Bhattacharya S. Transcriptional control of left-right patterning in cardiac development. Pediatr Cardiol 2010;31(3):371-377. https://doi.org/10.1007/s00246-009-9610-3.

12. Kosaki K1, Bassi MT, Kosaki R, et al. Characterization and mutation analysis of human LEFTY A and LEFTY B, homologues of murine genes implicated in left-right axis development. Kosaki Am J Hum Genet 1999;64(3):712-721.

13. Martínez-Frías ML. Heterotaxia as an outcome of maternal diabetes: An epidemiological study. Am J Med Genet 2001;99(2):142-146. https://doi.org/10.1002/1096-8628(2000)9999:999<00::AIDAJMG1139>3.0.CO;2-Z

14. Epperla N, Peterson E, Foy P. An unusual occurrence: a case of venous thromboembolism in pregnancy associated with heterotaxy syndrome. BMC Hematol 2015;15:7. https://doi.org/10.1186/ s12878-015-0025-5

15. Engelfriet $P$, Boersma E, Oechslin E, et al. The spectrum of adult congenital heart disease in Europe: morbidity and mortality in a 5-year follow-up period. The Euro Heart Survey on adult congenital heart disease. Eur Heart J 2005;26(21):2325-2333. https://doi.org/10.1093/eurheartj/ehi396

16. Presbitero P, Somerville J, Stone S, et al. Pregnancy in cyanotic congenital heart disease: Outcome of mother and fetus. Circul 1994;89(6):2673-2676. https://doi.org/10.1161/01.CIR.89.6.2673

17. Drenthen W, Boersma E, Balci A, et al. Predictors of pregnancy complications in women with congenital heart disease. Europ Heart J 2010;31(17):2124-2132. https://doi.org/10.1093/eurheartj ehq200

18. Weiss BM, Zemp L, Seifert B, Hess OM. Outcome of pulmonary vascular disease in pregnancy: A systematic overview from 1978 through 1996. J Am Coll Cardiol 1998;31(7):1650-1657. https://doi. org/10.1016/s0735-1097(98)00162-4

19. Pieper PG, Lameijer H, Hoendermis ES. Pregnancy and pulmonary hypertension. Best Pract Res Clin Obstet Gynaecol 2014;28(4):579-591. https://doi.org/10.1016/j.bpobgyn.2014.03.003

Accepted 12 November 2018 